\title{
The sunflower cataract in Wilson's disease: pathognomonic sign or rare finding?
}

\author{
Ewa Langwińska-Wośko ${ }^{1,2} \cdot$ Tomasz Litwin $^{1} \cdot$ Karolina Dzieżyc $^{1} \cdot$ Anna Członkowska ${ }^{1,3}$
}

Received: 11 October 2015/Accepted: 3 November 2015/Published online: 17 November 2015

(C) The Author(s) 2015. This article is published with open access at Springerlink.com

\begin{abstract}
The presence of Kayser-Fleischer ring in patients with Wilson's disease (WD) is well documented and included in diagnostic algorithms; however, data about the occurrence of the second postulated ophthalmological sign of WD, sunflower cataract (SC), are limited and even conflicting. The aim of our study was to verify the occurrence of SC in WD. From January 2010 to May 2015, 81 consecutive, newly diagnosed WD patients underwent detailed ophthalmological examinations, including slit lamp examination with special attention to lens transparency, to verify the presence of SC in WD-naive patients. SC was detected in only one $(1.2 \%)$ of the examined WD patients, did not impact visual acuity; moreover, completely disappeared following a year of treatment for WD. SC may be a very rare and reversible ophthalmological manifestation of WD that is observed seldom and only at the time of WD diagnosis. We postulate that a finding of $\mathrm{SC}$ in WD patients is an interesting finding that may occur in the course of WD, but it is not a pathognomonic sign of WD.
\end{abstract}

Keywords Wilson's disease - Kayser-Fleischer ring · Sunflower cataract $\cdot$ Lens

Tomasz Litwin

tomlit@medprakt.pl

1 Second Department of Neurology, Institute of Psychiatry and Neurology, Sobieskiego 9, 02957 Warsaw, Poland

2 Department of Ophthalmology, Medical University of Warsaw, Warsaw, Poland

3 Department of Experimental and Clinical Pharmacology, Medical University of Warsaw, Warsaw, Poland

\section{Introduction}

Wilson's disease (WD; OMIM No. 277900) is a genetic disorder of copper metabolism that results in copper accumulation in many tissues, mainly the liver, brain, cornea, and kidney. There is often secondary damage of affected organs and clinical manifestations related to the damaged organs [15]. The hepatic, neurological, and psychiatric signs and symptoms of WD are well described and characterized [1-7]. However, aside from the Kayser-Fleischer ring (K-F ring), which is produced by copper deposition in Descemet's membrane and is regarded as a typical sign of WD, ophthalmologic signs of WD are rarely mentioned in WD research papers [1-5, 8-14]. Sunflower cataract (SC) is considered a second ophthalmic sign of WD and has been called pathognomonic for WD [8-14]. SC consists of a thin, centralized opacification that is located directly under the anterior capsule and encompasses between one-third and one-half of the anterior lens pole surface area. In all cases, the central opacification is surrounded by additional, secondary opacifications arranged in ray-like structures around it. This pattern resembles a sunflower, with a large central disk surrounded by petals (Fig. 1).

The K-F ring is an important clinical sign that is included in WD diagnostic algorithms and measures of treatment efficacy [1]. SC was initially described as a pathognomonic sign for WD almost 90 years ago [9], and this description has been repeated often in WD review articles [1-5]. However, SC is not included in the diagnostic criteria for WD and has been reported rarely, even in case reports $[1,14]$. Potential reasons for the low occurrence of SC in WD patients are that it is an infrequent occurrence or that there is a lack of involvement of ophthalmologists who are experienced in SC diagnosis [9-13]. Because the ophthalmological manifestations of WD are 


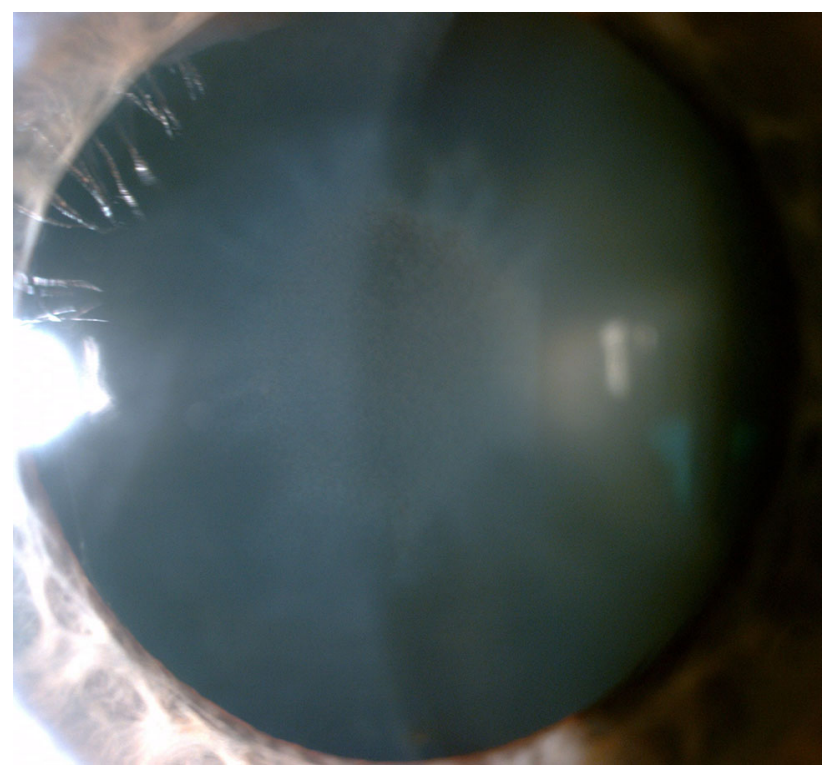

Fig. 1 Sunflower cataract (SC) seen with slit lamp at time of WD diagnosis

reversible, the aim of our study was to analyze the occurrence of SC in a cohort of untreated, newly diagnosed WD patients in order to verify the importance and frequency of this sign in association with WD.

\section{Materials and methods}

\section{Patients and methods}

We examined 81 consecutive, newly diagnosed WD patients between January 2010 and May 2015. All patients were diagnosed with WD according to international criteria [1]. Presymptomatic and neurologically and hepatically predominant forms of the disease were distinguished according to the presence and intensity of clinical signs and symptoms at the time of diagnosis, as previously described [3]. The study was approved by the bioethics committee of the institution, and written informed consent was obtained from all patients.

The one ophthalmologist conducted all of the examinations. All patients underwent formal ophthalmological examinations, including best-corrected visual acuity (BCVA), near vision, and slit lamp examination. The patients' pupils were then dilated ( $1 \%$ tropicamide), and lens examination was performed. Special attention was paid to lens transparency, and the occurrence of SC and K-F ring was noted.

\section{Statistical analysis}

All data were analyzed with Statistica v.10 (Stat Soft Inc., Tulsa, OK, USA). Mean, range, percentage, and standard deviation (SD) were measured for descriptive summary statistics.

\section{Results}

Demographic and clinical data of the WD patients involved in the study are presented in Table 1 . In our analysis of 81 WD patients, according to ophthalmological presentation of the disease, SC was found in only one WD patient $(1.2 \%)$, who exhibited an exclusive hepatic presentation. SC was found to have disappeared after 1 year of WD treatment with $d$-penicillamine.

The patient's SC did not impact visual acuity. The BCVA of the affected WD patient was 0.9 in the right eye, which was the more affected lens, and 1.0 in the left eye, with full near vision acuity. SC disappeared from both eyes after treatment for WD, with both eyes reaching 1.0 BCVA upon examination. We did not detect any other disturbances in lens transparency.

$\mathrm{K}-\mathrm{F}$ ring was identified in $67.9 \%(55 / 81)$ of the examined patients, and its frequency depended upon the phenotypic presentation of the disease. It was detected in $100 \%(34 / 34)$ and $57.5 \%$ (19/33) of patients with neurological and hepatic manifestation of the disease, respectively. Only $14.2 \%(2 / 14)$ of asymptomatic patients had K-F ring.

\section{Discussion}

The ocular symptoms K-F ring and SC have historically been considered pathognomonic for WD [1]. The occurrence of K-F ring in WD is well documented, and it is a key sign in diagnostic algorithms for the disease [1]. SC, first described in 1922 by Siemerling and Oloff [9], was also initially postulated as a sign associated with WD [1]. However, apart from single case reports and two small ophthalmological studies (53 and 32 nonhomogenous WD patients), which presented conflicting results regarding SC occurrence (1.9-17\%), there have been no reports documenting the occurrence and significance of SC in WD [1114].

To our knowledge, this was the first ophthalmological study in which the aim was to verify the occurrence and significance of SC in a relatively large cohort of newly diagnosed, untreated WD patients. We found a $1.2 \%$ occurrence of SC in untreated WD patients. According to this finding, $\mathrm{SC}$ is a very rare and perhaps even incidental ophthalmological finding in WD that, as with other copper accumulation WD symptoms (e.g., K-F ring and WD-associated brain magnetic resonance imaging changes), may 
Table 1 Demographic and clinical characteristics of the 81 analyzed WD patients

\begin{tabular}{ll}
\hline Gender & 34 \\
Men $(n)$ & 47 \\
Women $(n)$ & $28.6 \pm 11.4$ \\
Age at onset of WD symptoms (years) & $32.3 \pm 11.8$ \\
Age at WD diagnosis (years) & \\
Phenotypic forms of WD & 34 \\
Neurological $(n)$ & 33 \\
Hepatic $(n)$ & 14 \\
Asymptomatic $(n)$ & \\
Baseline copper metabolism parameters & $60.23 \pm 31.2$ \\
Ceruloplasmin, mg/dl (normal range 25-45 mg/dl) & $13.79 \pm 6.1$ \\
Serum copper level, $\mu \mathrm{g} / \mathrm{dl}$ (normal range & $328.6 \pm 854.9$ \\
$\quad 70-140 \mu \mathrm{g} / \mathrm{dl})$ & \\
Urine copper excretion, $\mu \mathrm{g} / 24 \mathrm{~h}$ (normal range \\
$\quad 0-50 \mu \mathrm{g} / 24 \mathrm{~h}$ ) \\
\hline
\end{tabular}

disappear during the course of disease treatment (as in our case) $[1-3,15,16]$.

The presence of SC appeared to have a limited effect on patient visual acuity. This should be emphasized, as classical cataracts usually have a marked effect on visual acuity. Cataract is caused by irreversible protein changes in the lens, leading to diminishing lens transparency and, consequently, reduced visual acuity. SC is not a "true" cataract, as it is caused by reversible copper deposition under the anterior capsule of the lens [10-14, 18]. Furthermore, we found no cases of "true" cataract in our group; this is probably due to the young age of the WD patients in this population.

In any discussion of the significance and occurrence of $\mathrm{SC}$ as a medical symptom, it is worth mentioning that similar ocular symptoms may occur in eyes with foreign bodies, including copper [19-21]. High copper ion levels in intraocular foreign bodies (IOFBs) may lead to chalcosis bulbi. This phenomenon is dependent on the copper ion concentration in IOFBs. If the copper concentrations level is over $85 \%$ it can produce inflammation with hypopyon, sterile endophthalmitis, and rapidly progress to phthisis. Chronic mild chalcosis (caused by IOFBs with copper concentration lower than $85 \%$ ) can produce K-F ring, SC and anterior chamber crystals [19-21]. However, unlike $\mathrm{K}-\mathrm{F}$ ring, SC has not yet been reported in other medical conditions in which increased serum copper levels occur (e.g., neoplastic disorders and estrogen intake) [17, 22-24]. In patients with $\mathrm{WD}$, the occurrence of $\mathrm{SC}$ has always been reported in patients with K-F ring, with both acting as ocular WD signs; to our knowledge, SC has never been reported as an isolated symptom in WD [17-24].
Our study also demonstrated the occurrence of K-F ring in WD patients; this is concordant with the results of previous studies. The frequency of K-F ring in WD patients is well documented and particularly affects patients with neurological presentation of the disease. However, our results also highlight the limitations of ophthalmological examinations when diagnosing WD in patients without neurological symptoms (especially presymptomatic patients) $[1,2]$.

A limitation of our study is that the group of analyzed patients could have been larger; however, this is the largest study group thus far of newly diagnosed WD patients who were examined for the presence of SC. Furthermore, our cohort was a homogenous group of patients who had not been treated previously.

\section{Conclusions}

SC is a very rare symptom of WD that may disappear following treatment. This may be of interest to specialists involved in the diagnosis and treatment of WD, as it is a rare WD symptom that may sometimes aid in definitive diagnosis [25]. The presence of SC, in combination with K-F ring could point physicians toward a WD diagnosis. However, due to the extreme rarity of its occurrence, as well as its occurrence in other medical conditions, such as the presence of foreign intraocular bodies containing copper, it should not be considered a pathognomonic ocular sign of WD.

Acknowledgments Karolina Dzieżyc is supported by the "START" stipend awarded by the Foundation for Polish Science.

\section{Compliance with ethical standards}

Conflict of interest The authors declare no conflict of interest.

Ethical approval The study protocol was approved by approved by the Medical University of Warsaw Bioethics Committee.

Financial disclosure All financial involvement (e.g., employment, consultancies, honoraria, stock ownership or options, grants or patents receiving or pending, and royalties) with any organization or entity with a financial interest in or financial conflict with the subject matter or materials discussed in the Submitted Publication material are completely disclosed.

Informed consent Informed consent was obtained from all individual participants included in the study.

Open Access This article is distributed under the terms of the Creative Commons Attribution 4.0 International License (http://creative commons.org/licenses/by/4.0/), which permits unrestricted use, distribution, and reproduction in any medium, provided you give appropriate credit to the original author(s) and the source, provide a link to the Creative Commons license, and indicate if changes were made. 


\section{References}

1. European Association for the Study of the Liver (2012) EASL clinical practice guidelines: Wilson's disease. J Hepatol 56(3):671-685

2. Dusek P, Litwin T, Czlonkowska A (2015) Wilson disease and other neurodegenerations with metal accumulations. Neurol Clin 33(1):175-204

3. Litwin T, Gromadzka G, Czlonkowska A (2012) Gender differences in Wilson's disease. J Neurol Sci 312(1-2):31-35

4. Pfeiffer R (2007) Wilson's disease. Semin Neurol 27(2):123-132

5. Bandmann O, Weiss KH, Kaler SG (2015) Wilson's disease and other neurological copper disorders. Lancet 14(1):103-113

6. Kayser B (1902) Uber einen Fall von angeborner grunlicher Verfarbung der Kornea. Klin Monatsbl Augenheilkd 40:22-25

7. Fleischer B (1903) Zwei weiterer Falle von grunlicher Verfarbung der Kornea. Klin Monatsbl Augenheilkd 41:489-491

8. Fleischer B (1912) Uber eine der "Pseudosklerose" nhestehende bisher unbekannte Krankheit (gekennzeichnet durch tremor, psychische storungen, brunliche Pigmentierung bestimmer gewebe, inbesondere uch der Hornhautperipherie, Lebecirrhose). Dtsch Z Nervenheilkd 44:179-201

9. Siemerling E, Oloff H (1922) Pseudoskleroses (WestphalStrumpell) mit Cornealring (Kayser-Fleicher) und doppelseitiger Scheinkatarakt, die nur bei seitlicher Beleuchtnung sichtbar ist und die der nach Verletzung durch Kupfersplitter entstehenden Katarakt anlich ist. Klin Wochenschr 1:1087-1089

10. Goyal V, Tripathi M (2000) Sunflower cataract in Wilson's Disease. J Neurol Neurosurg Psychiatry 69(1):133

11. Wiebers DO, Hollenhorst RW, Goldstein NP (1977) The ophthalmologic manifestations of Wilson's disease. Mayo Clin Proc 52(7):409-416

12. Huo LJ, Liao RD, Chen XM (2008) Ophthalmic manifestations of Wilson's disease. Zhonghua Yan Ke Za Zhi 44(2):128-130

13. Cairns JE, Parry Wiliams H, Walshe JM (1969) "Sunflower cataract” in Wilson's disease. Br Med J 3(5662):95-96
14. Cairns JE, Parry Wiliams H, Walshe JM (1970) The Kayser Fleischer ring. Trans Ophtalmol Soc 90:187-190

15. Tarnacka B, Szeszkowski W, Gołębiowski M, Czlonkowska A (2008) MR spectroscopy in monitoring the treatment of Wilson's disease patients. Mov Disord 23(11):1560-1566

16. Litwin T, Gromadzka G, Szpak GM, Jablonka-Salach K, Bulska E, Czlonkowska A (2013) Brain metal accumulation in Wilson's disease. J Neurol Sci 329(1-2):55-58

17. Suvarna JC (2008) Kayser-Fleischer ring. J Postgrad Med 54(3):238-240

18. Loßner A, Loßner J, Bachmann H, Zotter J (1986) The KayserFleischer ring during long-term treatment in Wilson's disease (hepatolenticular degeneration). Graefe's Arch Clin Exp Ophtalmol 224(2):152-155

19. Rosen E (1944) Chalcosis lentis associated with traumatic lenticonus posterior. Arch Ophthalmol 32(1):63-65

20. Parke DW III, Flynn HW, Fisher YL (2013) Management of intraocular foreign bodies: a clinical flight plan. Can J Ophthalmol 48(1):8-12

21. Ugarte M, Nicol DA, Jones NP, Charles SJ (2009) Chronic intraocular copper foreign body and candida: a unique combination. Ocul Immunol Inflamm 17(5):356-360

22. Fleming CR, Dickson ER, Hollenhorst RW, Goldstein NP, McCall JT, Baggenstoss AH (1977) Corneal pigmented rings in patients with primary biliary cirrhosis. Gastroenterology 69(1):220-225

23. Jawairia M, Subhani M, Siddiqui G, Prasad A, Shahzad G, Rizvon K, Mustacchia P (2012) Unexplained findings of KayserFleischer-like rings in a patient with cryptogenic cirrhosis. Case Rep Gastrointest Med 2012:438525

24. Garmizo G, Frauens BJ (2008) Corneal deposition secondary to oral contraceptives. Optom Vis Sci 85(9):E802-E807

25. Litwin T, Langwinska-Wosko E, Dziezyc K, Czlonkowska A (2015) Sunflower cataract: do not forget Wilson's disease. Pract Neurol 15:385-386 